\title{
Definite Adverse Event Attribution to Product or Procedure
}

National Cancer Institute

\section{Source}

National Cancer Institute. Definite Adverse Event Attribution to Product or Procedure. NCI Thesaurus. Code C41356.

Definite adverse event attribution to study product or procedure is established when there is a clear-cut temporal association between product or procedure administration and adverse event, and no other possible cause is present. 